\title{
Forewarning, meaning, and semantic decision latency '
}

\author{
NICHOLAS L. ROHRMAN ${ }^{2}$ AND PHILIP B. GOUGH ${ }^{3}$ \\ INDIANA UNIVERSITY
}

Twelve Ss were asked to decide if pairs of nonsense syllables were identical or different. A second group of 12 Ss was asked to decide if pairs of words were synonymous or not. Prior to each pair all Ss were given either one member of the pair, an unrelated item of the same type, or the word "set." Decisions about nonsense syllables were made faster than ones for words, and type of forewarning was also significant. In a second experiment $16 \mathrm{Ss}$ were asked to judge the synonymity of 16 pairs of words where one was rare and one common. Ss had true and false forewarning. Forewarning was significant, but did not differentially effect judgments on rare and common words.

Several experiments (Fillenbaum, 1964; Gumenik \& Perlmutter, 1965; Gough \& Rohrman, 1965) have shown that if someone is asked to decide if a pair of words are synonyms, his decision is greatly facilitated if he is given one of the words in advance. This paper reports two experiments concerned with the explanation of this forewarning effect. In a previous paper (Gough \& Rohrman, 1965) the following explanation was suggested: To compare two words and decide if they have the same meaning, $S$ must compare their meanings. To compare their meanings $S$ must first retrieve them, and it can be assumed that this retrieval process occupies some measurable duration. When $S$ is forewarned, retrieval of one of the meanings-that of the forewarned word-is achieved ahead of time, and thus, upon presentation of the decision pair, $S$ has only to retrieve the meaning of the remaining word and compare the two meanings. The decision latency following forewarning should be reduced accordingly, due to the elimination of the retrieval process of the meaning of one word from the task.

This hypothesis has at least two testable implications. First, the hypothesis that forewarning produces its effect by subtracting the duration of the retrieval of a meaning from the decision latency, clearly implies that the effect depends upon meaning. If there were no retrieval process for the $S$ to perform, forewarning should have no effect. For example, if $S$ were simply asked to decide if a pair of meaningless items such as nonsense syllables were the same or different, the decision latency should not be affected by forewarning. Experiment 1 tested this prediction.

\section{EXPERIMENT 1}

\section{Method}

Twelve Ss drawn from introductory psychology courses were given 24 pairs of CCC nonsense syllables to be judged identical or different. Half of the pairs were identical, half were different; the different pairs had no letter in common. A second group of 12 Ss was given 24 pairs of words to be judged synonymous or not; half of the pairs were synonymous, half of them were unrelated words. For both groups, presentation of each pair in a tachistoscope started a standard electric timer, and $\mathrm{S}$ indicated his decision by pressing a button which stopped the timer. Two sec prior to each pair, each $\mathrm{S}$ in both groups was read either one member of the pair (True Forewarning), an unrelated item of the same type (False Forewarning), or simply the word "set" (No Forewarning). Decision latencies under each type of forewarning with each type of decision were recorded.

\section{Results and Discussion}

The results are presented in Table 1. Analysis of variance of these data revealed a significant effect of type of decision $(F=48.27, \mathrm{df}=1 / 22, \mathrm{p}<.01)$. Decisions that nonsense syllables were identical or not were made faster than decisions concerning the synonymity of words.

The effect of type of forewarning was also significant $(F=7.73$, df $=2 / 44, p<.01$ ), but a highly significant interaction between forewarning and type of decision ( $F=6.78, \mathrm{df}=2 / 44, \mathrm{p}<.01$ ) shows that the effects of forewarning are not the same on both types of decision. Examination of Table 1 reveals the source of this interaction. True Forewarning facilitated decisions of synonymity, while False Forewarning retarded those decisions, relative to No Forewarning. But forewarning had no effect whatsoever on decisions concerning the identity or difference of two nonsense syllables. These results, then, confirm the hypothesis that the effect of forewarning on decision latency depends on the involvement of meaning in the decision, and they indirectly support the hypothesis that the forewarning effect is achieved by subtracting one retrieval task from the decision period.

That hypothesis has a second testable consequence. If the forewarning effect depends upon the elimination of a retrieval task, then the size of that effect should depend upon the magnitude-the difficulty - of the re-

Table 1

Mean decision latency, as a function of type of decision and forewarning, Experiment 1

\begin{tabular}{llrrr}
\hline & & & Forewarning & \\
& & True & False & None \\
Decision & Synonymity of Word Pairs & 1.30 & 1.56 & 1.46 \\
& Identity of Nonsense & .76 & .76 & .78 \\
& Syllable Pairs & & & \\
\hline
\end{tabular}


Table 2

Mean decision latency as a function of type of forewarning and frequency of forewarning word, Experiment 2

\begin{tabular}{llrr} 
& & \multicolumn{2}{c}{ Forewarning } \\
& & True & False \\
Frequency & Rare & 1.38 & 1.82 \\
& Common & 1.43 & 1.66 \\
\hline
\end{tabular}

trieval task that is eliminated. It seemed probable that the difficulty of retrieval of a word's meaning is related to that word's frequency of usage. This suggests that the retrieval of the meaning of a rare word will take longer than the retrieval of the meaning of a common word. It follows that if a $S$ were judging the synonymity of a pair of words, one rare and one common, that forewarning him of the rare word should facilitate his decision more than forewarning him of the common one. Experiment 2 was conducted to test this hypothesis.

\section{EXPERIMENT 2}

\section{Method}

Sixteen Ss were asked to judge the synonymity of 16 pairs of words and their decision latencies were measured. In each pair, one word was rare (less than 10 in the Thorndike-Lorge G count, Thorndike \& Lorge, 1944), one common (AA). Half of the pairs were synonyms, half were unrelated in meaning. On half of the pairs, the $S$ received true forewarning, and on half of them false forewarning. In each case, half of the time $S$ was forewarned on the rare word, half of the time on the common one. Two series of these eight types were presented to each S. Pair content was completely counterbalanced across Ss and conditions. The items presented to each $S$ thus constitute $a 2$ by 2 by 2 design with repeated measures, True vs False Forewarning by Rare vs Common Forewarning by Series.

\section{Resulis and Discussion}

The results are presented in Table 2. Analysis of variance showed the usual significant forewarning effect $(F=22.88$, df $=1 / 15, p<.01)$, but it failed to reveal the predicted interaction between True or False Forewarn- ing and the frequency of the forewarned word $(F=3.27$, $\mathrm{df}=1 / 15, \mathrm{p}>.05)$. The forewarning effect-the difference between True and False Forewarning-was substantially larger when $S$ was forewarned of the rare word than when he was forewarned of the common one, but the difference was not significant. No other significant effects were observed.

This result would seem to indicate either that the size of the forewarning effect does not depend on the duration of the retrieval process eliminated by forewarning or that duration of retrieval is not related to frequency of usage. The latter is an especially intriguing hypothesis, but the present study suffered from a difficulty which endangers such a conclusion. A difference in the predicted direction was obtained, but it could not overcome the enormous variance involved in the contrast. Rare words (less than 10 in Thorndike-Lorge) whose meanings it was thought would be difficult to retrieve were used in comparison with common ones (Thorndike-Lorge AA). Many Ss did not know the meanings of these rare words and, as a result, there are a number of very large latencies in the data which are associated with random guesses as to synonymity. Thus sampling a population of Ss with larger vocabularies might provide data which will allow a comparison to be made without confounding from lack of meaning.

\section{References}

FILLENBAUM, S. Semantic satiation and decision latency. $J$. exp. Psychol, 1964, 68, 240-244.

GOUGH, P. B., \& ROHRMAN, N. L. Semantic satiation, forewarning, and decision latency. Psychon. Sci, 1965, 2, 387-388.

GUMENIK, W. E., \& PERLMUTTER, E. S. Verbal repetition, set, and decision latency. Paper read at Midwest. Psychol. Assoc. meeting, Chicago, May, 1965.

THORNDIKE, E. L., \& LORGE, I. The teacher's word book of 30,000 words. New York: Teachers College, Columbia, 1944.

Notes

1. This study was supported by USPHS Grant MH 11869-01 to the junior author. These results were presented at the meetings of the Midwestern Psychological Association, Chicago, May, 1966.

2. Now at Bucknell University, Lewisburg, Pennsylvania.

3. Now at the University of Texas, Austin, Texas. 